\title{
Pelatihan Pembuatan dan Pengembangan Pupuk Organik Cair Biokultur dan Biourin untuk Mendukung Sistem Budidaya Sayuran Organik
}

\author{
Training on the Making and Development of Bioculture and Biourine Liquid Organic \\ Fertilizers to Support the Organic Vegetable Cultivation System
}

Sri Anjar Lasmini*
Idham
Anthon Monde
Tarsono
Department of Pests and Plant
Diseases, Universitas Tadulako, Palu,
Central Sulawesi, Indonesia
"email: srianjarlasmini@gmail.com
Kata Kunci
Pupuk Organik Cair
Biokultur
Biourin
Budidaya Sayuran Organik
Keywords:
Liquid Organic Fertilizer
Bioculture
Biourine
Organic Vegetable Cultivation
Pccepted: July 2019
Published: September 2019

\begin{abstract}
Abstrak
Dalam pengembangan usaha tani sayuran oleh masyarakat dijumpai permasalahan mendasar yakni umumnya dilaksanakan secara konvensional dengan penggunaan pupuk dan pestisida sintetik menjadi penentu keberhasilan usahataninya. Dengan sistem usaha tani tersebut masyarakat mengalami banyak kerugian karena saprodi yang digunakan tergolong mahal dan di sisi lain hasil produk menjadi murah karena belum terjamin kualitasnya. Solusi atas permasalahan tersebut adalah dengan mengembangkan pupuk organik Biokultur dan biourin yang bahan bakunya tersedia di wilayah tersebut. Program pengembangan desa mitra bertujuan untuk melakukan pelatihan pembuatan dan pengembangan pupuk organik cair bioukultur dan biourin untuk mendukung budidaya sayuran organik.. Metode pendekatan yang diterapkan adalah technology transfer (TT) dan entrepreneurship capacity building (ECB) yang dilaksanakan dengan pendekatan Partisipatory Rural Approach (PRA) yang dalam pelaksanaannya menggunakan metode ceramah/diskusi, pelatihan, pembuatan demo plotting, dan pendampingan. Hasil yang dicapai dalam pelaksanaan program ini yaitu peserta sudah mampu membuat dan mengembangkan pupuk organik cair biokultur dan biourin dan mengaplikasikan ke lahan usaha taninya sebagai alternatif pengganti pupuk kimia.
\end{abstract}

\begin{abstract}
In the development of vegetable farming by the community, there are fundamental problems which are generally carried out conventionally with the use of synthetic fertilizers and pesticides to determine the success of their farming. With the farming system, the community suffers a lot of losses because the inputs used are relatively expensive and on the other hand the products become cheap because the quality is not guaranteed. The solution to this problem is to develop bio-culture organic fertilizers and bio-urine whose raw materials are available in the region. The partner village development program aims to conduct training on the making and development of liquid organic fertilizer bio-culture and biourine to support the cultivation of organic vegetables. The method of approach applied is technology transfer (TT) and entrepreneurship capacity building (ECB) which is carried out with the Participatory Rural Approach (PRA) approach ) which in its implementation uses the method of lecture/discussion, training, making demo plotting, and assistance. The results achieved in the implementation of this program were that participants were able to make and develop liquid organic bioculture fertilizers and biourin and apply it to their farms as an alternative to chemical fertilizers.
\end{abstract}




\section{PENDAHULUAN}

Unit Permukiman Transmigrasi Daerah (UPTD) Bulupountu Jaya Kecamatan Sigi Biromaru termasuk salah satu sentra produksi tanaman hortikultura khususnya tanaman sayur-sayuran di Kabupaten Sigi yang turut mensuplai kebutuhan sayuran di Kota Palu. Masyarakat yang bermukim di UPTD Bulupountu Jaya umumnya berasal dari Nusa Tenggara Barat (NTB), Nusa Tenggara Timur (NTT), Jawa Timur, dan Jawa Tengah, dengan pekerjaan utama adalah petani. Sebagai salah satu daerah yang mensuplai kebutuhan sayuran di Kota Palu, masyarakatnya secara rutin melakukan budidaya sayuran berumur pendek seperti kangkung, bayam, bawang daun, bunga kol, kubis, tomat, cabe, terong, paria, kemangi, berbagaijenis buah-buahan segar seperti pepaya dan semangka. Areal pengembangan komoditi sayuran tersebut cukup luas yakni mencapai 250 ha (Badan Pusat Statistik Kabupaten Sigi, 2016).

Dalam pengembangan usaha tani sayuran umumnya dilaksanakan secara konvensional dengan penggunaan pupuk dan pestisida sintetik menjadi penentu keberhasilan usahataninya. Sistem pertanian konvensional memang dapat melipatgandakan hasil panen, namun dampak negatifnya dapat menimbulkan terjadinya kerusakan lingkungan berupa menurunnya tingkat kesuburan tanah sehingga lahan pertanian menjadi rusak (Mayrowani, 2012). Untuk mengatasi hal tersebut maka perlu dilakukan upaya mengurangi penggunaan pupuk kimia melalui pemanfaatan sumberdaya lokal berupa kotoran ternak dan limbah hasil pertanian sebagai sumber pupuk organik. Pemberian pupuk organik pada tanah berperan penting dalam memperbaiki struktur tanah seperti aerasi udara lebih baik dan pergerakan air lancar, sehingga mampu meningkatkan pertumbuhan dan produksi tanaman (Lasmini et al., 2015; Widawati et al., 2002).
Pupuk organik dapat berupa pupuk padat maupun pupuk cair. Penggunaan pupuk organik cair mempunyai beberapa keuntungan, seperti struktur tanah yang lebih baik, mudah dan cepat diserap oleh Tanaman. Selain itu pupuk organic juga meningkatkan hara tersedia bagi tanaman dan meningkatkan populasi serta aktivitas mikroba tanah (Suliasih et al., 2010).

Biokultur dan biourin merupakan salah satu pupuk organik cair yang terbuat dari campuran substrat enzim hayati, kellat hayati kompleks, vitamin, dan garam elektrolit serta air (Arham et al., 2014, Hadi, 2005). Aplikasi pupuk organik cair biokultur dan biourin dapat meningkatkan pertumbuhan dan hasil tanaman dan meningkatkan kualitas tanah dengan memperbaiki sifat fisik, kimia dan biologi tanah (Nuraini \& Asgianingrum, 2017; Lasmini et al., 2017; Santoso et al., 2015). meningkatkan populasi mikroba tanah (Ouda \& Mahadeen, 2008; Pangaribuan et al., 2017; Shaheen et al., 2007), Serta menekan perkembangan patogen tanah (Gotora et al., 2014; Arham et al., 2014). Pada tanaman bawang merah, aplikasi biokultur dengan frekuensi 4 kali pemberian dapat meningkatkan hasil umbi (Lasmini et al., 2018).

Kotoran ternak dan limbah hasil pertanian sebagai sumber pupuk organik cair termasuk sumberdaya yang cukup melimpah di UPTD Bulupountu Jaya. Data Statistik Kecamatan Sigi Biromaru menunjukkan bahwa jumlah ternak sapi di UPTD sebanyak 119 ekor dan ternak kambing sebanyak 278 ekor (Badan PusatStatistik Kabupaten Sigi, 2016). Dengan memanfaatkan limbah kotoran ternak selain mengurangi pencemaran lingkungan juga dapat meningkatkan nilai tambah dari limbah tersebut.

Permasalahan yang dijumpai dalam pemanfaatan limbah ternak dan tanaman di UPTD Bulupountu Jaya adalah pengetahuan dan keterampilan kelompok masyarakat masih tergolong rendah sehingga adopsi 
teknologi berjalan lamban. Program pengabdian kepada masyarakat skema PPDM ini bertujuan untuk melatih masyarakat (kelompok tani) memafaatkan limbah ternak menjadi pupuk organik cair bioukultur dan biourin untuk diaplikasikan pada lahan usaha taninya sebagai alternatif pengganti pupuk kimia melalui sistem budidaya sayuran organik.

\section{METODOLOGI}

Metode pendekatan yang digunakan dalam pelaksanaan program PPDM adalah:

1. Partisipatory Rural Approach (PRA), yaitu pendekatan partisipatif yang melibatkan masyarakat pada semua tahap kegiatan mulai dari perencanaan pelaksanaan hingga evaluasi.

2. Technology Transfer (TT), yaitu dalam pensolusian masalah bertumpu kepada transfer inovasi teknologi tepat guna kepada masyarakat sasaran untuk meningkatkan kinerja dan produktivitas usaha masyarakat.

3. Entrepreneurship Capacity Building (ECB), yaitu membangun wawasan kewirausahaan masyarakat melalui pembentuk kelompok usaha bersama (KUBE).

Metode yang digunakan dalam melaksanakan PPDM adalah:

1. Ceramah/diskusi, Metode ini dinilai lebih efektif memberikan pengetahuan dasar tentang program yang akan dilaksanakan dengan didukung modulmodul praktis.

2. Pelatihan, bertujuan untuk meningkatkan ketrampilan masyarkat dalam aplikasi inovasi teknologi.

3. Pembuatan demo ploting yaitu praktek aplikasi teknologi di lapangan agar masyarakat bisa melihat secara langsung terapannya dalam kehidupan nyata,
4. Pendampingan, yaitu pembinaan secara berkala dan berkelanjutan mengenai adopsi/aplikasi teknologi dalam praktek langsung pada tingkat masyarakat.

Pada pelaksanaan pelatihan, peserta dikelompokkan menjadi 2 kelompok kerja yaitu kelompok kerja pembuatan biokultur dan kelompok kerja pembuatan biourin yang masing-masing kelompok terdiri atas 10 orang. Pada setiap kelompok kerja didampingi oleh 2 orang tenaga ahli (tim pelaksana program PPDM) dan 2 orang mahasiswa. Kegiatan pelatihan dilaksanakan selama 1 (satu) bulan yaitu pada bulan Mei 2019 dan dilanjutkan dengan pendampingan masyarakat selama 2 (dua) bulan yaitu bulan Juni sampai dengan Juli 2019.

\section{HASIL DAN PEMBAHASAN}

Kegiatan pelatihan pembuatan pupuk organik cair biokultur dan biourin ditujukan kepada masyarakat tani di UPTD Bulupountu Jaya. Kegiatan tersebut diharapkan membuka wawasan untuk menerima informasi dan teknik pembuatan dan pengembangan pupuk organik cair bioukultur dan biourin serta teknik pengaplikasiannya pada lahan usahataninya. Dengan program pelatihan tersebut masyarakat mendapatkan pengetahuan dan ketrampilan dalam memanfaatkan sumberdaya keluarga yang selama ini tidak termanfaatkan. Pemanfaatan limbah ternak menjadi pupuk organik juga sekaligus mengurangi pencemaran lingkungan di sekitar tempat tinggal masyarakat serta dapat menjadi tambahan pendapatan usaha rumah tangga melalui usaha penjualan pupuk organik cair biokultur dan biourin.

\section{Pembuatan Pupuk Organik Cair Biokultur dan Biourin}

Proses pembuatan pupuk organik cair biokultur dan biourin pada prinsipnya sama, hanya pada pembuatan pupuk organik cair biokultur menggunakan feses sapi segar sedangkan pada pembuatan biourin tidak menggunakan feses sapi. Pembuatan pupuk organik cair 
biokultur urin sapi dilakukan dengan pentahapan sebagai berikut:

1. Urin sapi segar sebanyak 5 liter dan kotoran (feses) sapi sebanyak $5 \mathrm{~kg}$ dimasukkan ke dalam wadah (ember) berukuran 100 liter kemudian ditambahkan dengan air sebanyak 50 liter dan selanjutnya dicampur menjadi larutan

2. Larutan ditambahkan kellat hayati (Fe kellat) sebanyak 70 cc dan bakteri fermentasi (EM4) sebanyak $50 \mathrm{ml}$ serta ekstrak tumbuhan lengkuas, kunyit, dan kencur masing-masing sebanyak 1 ons dan ekstrak sereh wangi sebanyak 10 batang

3. Larutan yang telah ditambahkan dengan bahanbahan tersebut selanjutnya di aduk/kocok secara merata sampai semua bahan menjadi larutan yang homogen.

4. Setelah larutan sudah homogen maka wadah ember yang digunakan ditutup dan pada penutup ember dibuat lubang sebesar lubang selang plastik ukuran diameter $1 \mathrm{~cm}$.

5. Larutan tersebut diaduk dengan aerator yang salah satu ujungnya telah dihubungkan denganarus listrik dan pada ujung yang lain dimasukkan ke dalam wadah ember melalui lubang yang telah dibuat sebelumnya.

6. Pengadukan dilakukan selama 3 minggu (selama proses fermentasi) dan selang setiap minggu larutan tersebut diperiksa untuk menguapkan amoniak yang bersifat racun bagi tanaman.

7. Pada minggu ke 4, penutup ember dibuka untuk mengambil larutan bagian atas (cair), sedangkan larutan bagian bawah yang mengendap (padat) diperas/dan hasil perasannya dicampur kembali dengan larutan sebelumnya.

8. Pembuatan pupuk organik cair biokultur urin sapi dianggap berhasil apabila larutan yang dihasilkan berubah warna menjadi warna coklat kekuningan dan tidak berbau.

9. Hasil perasan yang berupa larutan disaring dan dimasukan kedalam wadah (jerigen) kemudian ditutup (inilah hasil pupuk organik cair biokultur urin sapi).

10. Selanjutnya pupuk organik cair (POC) biokultur urin sapi ini siap diaplikasikan pada pertanaman sayuransaayuran dengan dosis sesuai yang direkomendasikan misalnya pada tanaman bawang merah dengan dosis 750 1/ha (Lasmini et al., 2018).

Dokumentasi pembuatan pupuk cair biokultur serta pengembangan pupuk cair biokultur oleh peserta disajikan pada Gambar 1 sampai 4.

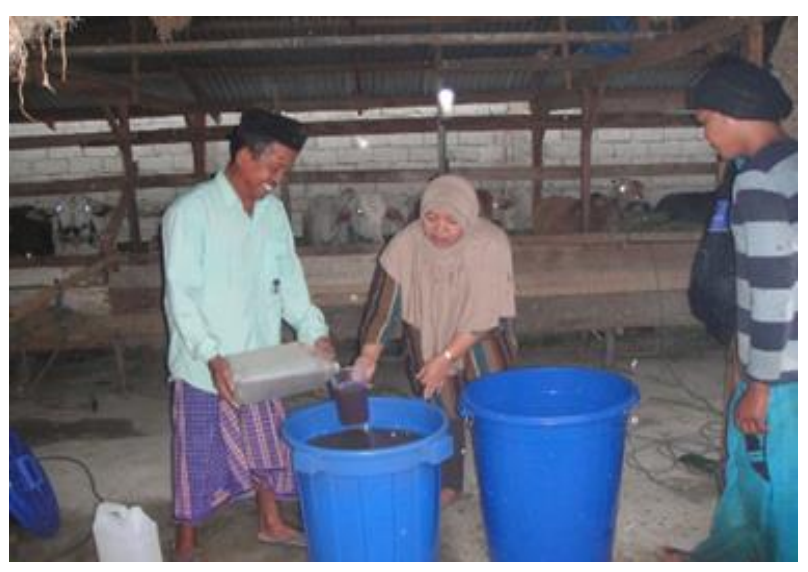

Gambar 1. Proses pembuatan pupuk cair biokultur

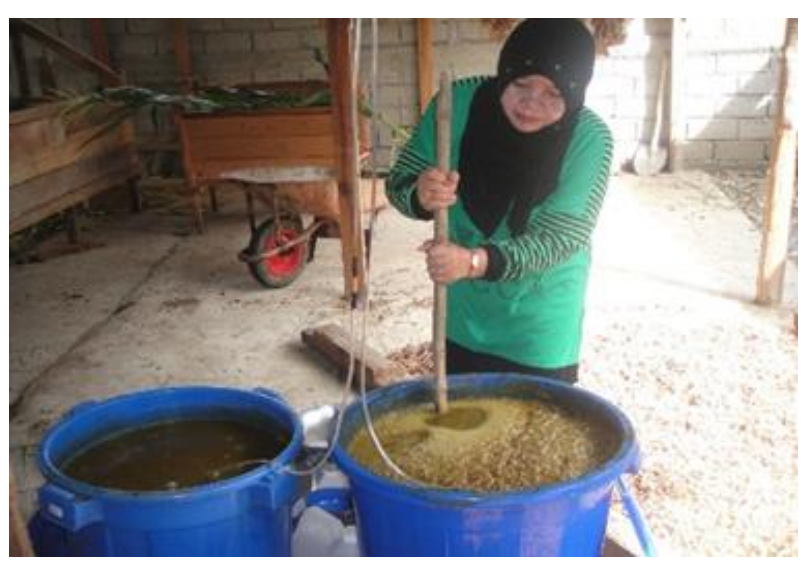

Gambar 2. Proses pembuatan pupuk cair biokultur 


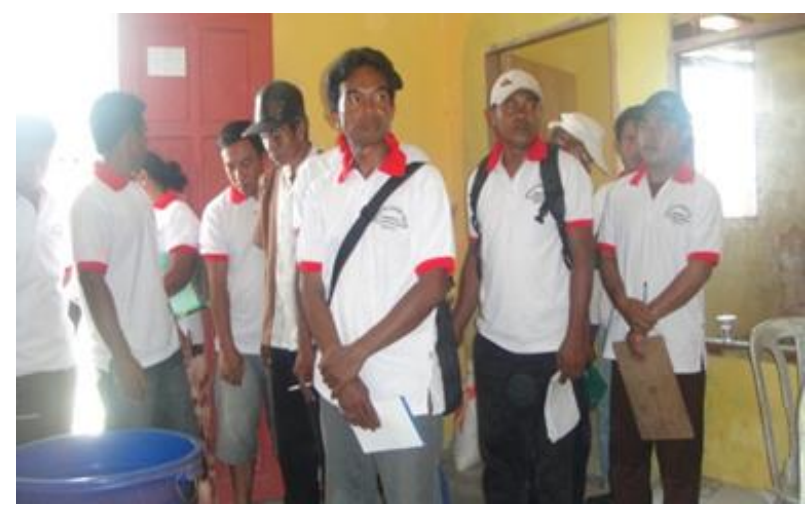

Gambar 3. Peserta pelatihan mengamati proses pengembangan pupuk cair biokultur

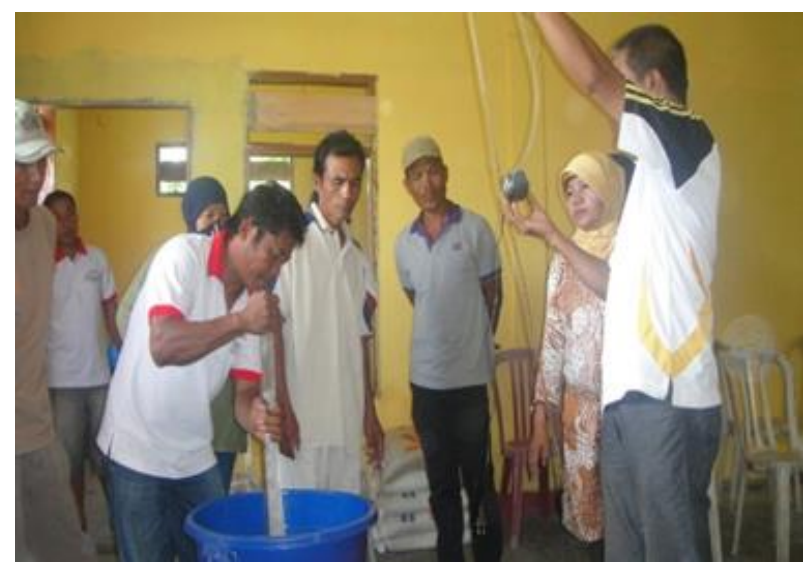

Gambar 4. Peserta pelatihan melaksanakan pengembangan pupuk cair biokultur

\section{Teknik Aplikasi pupuk organik cair biokultur pada tanaman}

Untuk aplikasi pupuk organik cair biokultur dan biourin pada lahan siap tanam dilakukan dengan cara menyiramkan dengan rata dengan dosis yang sudah ditentukan sedangkan aplikasi pada tanaman yang sudah tumbuh dilakukan dengan menyemprotkan menggunakan knapsack sprayer

\section{Pembinaan dan Pendampingan dan Evaluasi}

Pembinaan dan pendampingan terhadap kelompok sasaran dilaksanakan setelah kegiatan penyuluhan dan pelatihan telah selesai dilaksanakan. Pelaksanaan kegiatan tersebut dimaksudkan untuk memantapkan kapasitas dan kemampuan masyarakat untuk secara mandiri mengembangkan pupuk organik berbahan baku limbah ternak dan membuat produk yang sesuai dengan permintaan konsumen, bahkan memfasilitasi petani untuk membangun usaha bisnis baru. Selanjutnya, evaluasi kegiatan dimaksudkan untuk mengetahui tingkat keberhasilan aplikasi teknologi pembuatan pupuk organik cair bioukltur dan biourin. Kadangkala sebuah aplikasi teknologi dapat dilaksanakan oleh masyarakat pada saat pelatihan berlangsung, namun karena terdapat kerumitan dalam pelaksanaannya, maka dibutuhkan perbaikan teknik yang dapat dengan mudah diadaptasikan sesuai dengan kapasitas masyarakat sasaran.

\section{KESIMPULAN}

Pada pelaksanaan program pengabdian kepada masyarakat ini dapat disimpulkan bahwa pelaksanaan pelatihan pembuatan pupuk cair biokultur dan biourin kepada kelompok masyarakat berlangsung dengan baik dan dapat diadopsi oleh masyarakat, hal tersebut diindikasikan oleh antusiasme peserta dalam mengikuti kegiatan pelatihan tersebut. Pembuatan pupuk cair biokultur dan biourin yang dilakukan oleh peserta kegiatan (anggota kelompok tani mitra) berlangsung dengan baik dan dapat menghasilkan pupuk organik cair yang dapat digunakan sebagai pengganti pupuk kimia sintetis dalam berusaha tani.

\section{UCAPAN TERIMA KASIH}

Program PPDM ini terlaksana atas pendanaan dari Direktorat Riset dan Pengabdian Kepada Masyarakat Direktorat Jenderal Penguatan Riset dan Pengembangan Kementerian Riset, Teknologi dan Pendidikan Tinggi Sesuai dengan Perjanjian Penugasan Pelaksanaan Program Pengabdian Masyarakat Nomor: 100/SP2H/LT/DRPM/2019, tanggal 11 Maret 2019.

\section{REFERENSI}

Arham, Samudin, S., Madauna, I. 2014. Frekuensi Pemberian Pupuk Organik Cair dan Berbagai 
Jenis Mulsa Terhadap Pertumbuhan dan Hasil Bawang Merah (Allium ascalonicum L.) Varietas Lembah Palu. Agrotekbis: E-Jurnal Ilmu Pertanian. 2(3):237-248.

Badan Pusat Statistik Kabupaten Sigi. 2016. Kecamatan Sigi Biromaru Dalam Angka, 2016. Sigi: Badan Pusat Statistik Kabupaten Sigi Sulawesi Tengah.

Gotora, T., Masaka, L., Sungirai, M. 2014. Effect of Cow Urine on the Growth Characteristics of Fusarium lateritium, an Important Coffee Fungus in Zimbabwe. International Journal of Agronomy. $\quad$ 2014(986068):1-4. http://dx.doi.org/10.1155/2014/986068

Hadi, S. 2005. Agricultural enzymatic technology (in Indonesian). Paper presented at "Agricultural Information and Technology Summit". A meeting of all farmers and agricultural extension in North Sumatra. Medan. October 25, 2005.

Lasmini, S.A., Kusuma, Z., Santoso, M., Abadi, A.L. 2015. Application of Organic and Inorganic Fertilizer Improving the Quantity and Quality of Shallot Yield on Dry Land. International Journal of Scientific \& Technology Research. 4(4):243-246.

Lasmini, S.A., Wahyudi, I., Nasir, B., Rosmini. 2017. Pertumbuhan dan Hasil Bawang Merah Lembah Palu pada Berbagai Dosis Pupuk Organik Cair Biokultur Urin Sapi. Agroland: Jurnal Ilmu-Ilmu Pertanian. 24(3):199-207. http://dx.doi.org/10.22487/J.24077607.2017. v24.i3.9703

Lasmini, S.A., Wahyudi, I., Rosmini. 2018. Aplikasi Mulsa dan Biokultur Urin Sapi terhadap Pertumbuhan dan Hasil Bawang Merah. Jurnal Hortikultura Indonesia (JHI). 9(2):103-110. https://doi.org/10.29244/jhi.9.2.103-110

Mayrowani, H. 2012. Pengembangan Pertanian Organik di Indonesia. Forum Penelitian Agro Ekonomi. 30(2):91-108. http://dx.doi.org/10.21082/fae.v30n2.2012.9 $\underline{1-108}$

Nuraini, Y., Asgianingrum, R.E. 2017. Peningkatan Kualitas Biourin Sapi dengan Penambahan Pupuk Hayati dan Molase serta Pengaruhnya terhadap Pertumbuhan dan Produktivitas Pakchoy. Jurnal Hortikultura Indonesia (JHI).
8(3):183-191.

https://doi.org/10.29244/jhi.8.3.183-191

Ouda, B.A., Mahadeen, A.Y. 2008. Effect of fertilizers on growth, yield, yield components, quality and certain nutrient contents in broccoli (Brassica oleracea). International Journal of Agriculture and Biology. 10(6):627-632.

Pangaribuan, D.H., Ginting, Y.C., Saputra, L.P., Fitri, H. 2017. Aplikasi Pupuk Organik Cair dan Pupuk Anorganik terhadap Pertumbuhan, Produksi, dan Kualitas Pascapanen Jagung Manis (Zea mays var. Saccharata Sturt.). Jurnal Hortikultura Indonesia $\quad$ (JHI). $8(1): 59-67$. https://doi.org/10.29244/jhi.8.1.59-67

Santosa, M., Suryanto, A., Maghfoer, M.D. 2015. Application of Biourine On Growth and Yield of Shallot Fertilized with Inorganic and Organic Fertilizer in Batu, East Java. Agrivita: Journal of Agricultural Science. 37(3):290-295. http://doi.org/10.17503/agrivita.v37i3.621

Shaheen, A.M., Fatma, A.R., Singer, S.M. 2007. Growing Onion Plants Without Chemical Fertilization. Research Journal of Agriculture and Biological Sciences. 3(2):95-104.

Suliasih, S., Widawati, S., Muharam, A. 2010. Aplikasi Pupuk Organik dan Bakteri Pelarut Fosfat untuk Meningkatkan Pertumbuhan Tanaman Tomat dan Aktivitas Mikroba Tanah. Jurnal Hortikultura (Journal of Horticulture). 20(3):241246.

http://dx.doi.org/10.21082/jhort.v20n3.2010. $\mathrm{p} \% 25 \mathrm{p}$

Widawati, S., Suliasih, S., Syaifudin, S. 2002. Pengaruh Introduksi Kompos Plus terhadap Produkasi Bobot Kering Daun Kumis Kucing (Orthosiphon aristatus) pada Tiga Macam Media Tanah. Jurnal Biologi Indonesia. 3(3):245253. http://dx.doi.org/10.14203/jbi.v3i3.3475 